\title{
Chest Wall Sarcoma
}

National Cancer Institute

\section{Source}

National Cancer Institute. Chest Wall Sarcoma. NCI Thesaurus. Code C155873.

A sarcoma that arises from the anatomic structures that surround the lungs and the pleura. 